\title{
Migration to European Countries: A Structural Explanation of Patterns, 1980-2004
}

\author{
Marc Hooghe \\ Ann Trappers \\ Bart Meuleman \\ Tim Reeskens \\ Catholic University of Leuven (Belgium)
}

Various theoretical approaches have provided us with insights to explain the pattern of migration flows. Economic theory considers migration to be a reaction to labor market and economic incentives. Cultural theories predict that migration flows will occur according to a center-periphery pattern, while social network analysis assumes that migrants follow already established migration networks. We test these three approaches simultaneously, using OECD and Eurostat data on the migrant inflow into the European countries between 1980 and 2004. The analysis demonstrates that migration flows react to economic incentives, mainly with regard to the labor market, but also to cultural and colonial linkages. There is no indication that the importance of the colonial past is declining over time. The response of migration patterns to shortages in the labor market is shown to be highly efficient, while the analysis shows that immigrants are not attracted by high levels of social expenditure.

\section{INTRODUCTION}

Since the 1960s migration to Western Europe has increased substantially, despite the fact that since the early 1970s various countries have adopted restrictive legislation with regard to the entry of foreigners into the country (Castles and Miller, 2003; Krieger, 2004; OECD, 2006). These legal obstacles apparently have not prevented an ever-increasing number of persons to settle in Western Europe, either in the form of economic or labor migrants, political asylum seekers, or in the form of various procedures with regard to family reunification (Zlotnik, 1998). We know far less, however, about why migrants

${ }^{1}$ The authors wish to thank Jaak Billiet and Johan Leman for their constructive comments on an earlier version of this article. We also want to acknowledge the KU Leuven Research Council and the Fund for Scientific Research-Flanders (FWO-Vlaanderen) for their support for this research project. 
specifically decide to settle in a particular country and why they tend to avoid others. Furthermore, these preferences seem to shift over time. In recent years, e.g., the countries in southern Europe have experienced a huge increase in the number of people seeking entrance into the country (Venturini, 2004). If we assume that migrants typically seek better living conditions (Kalter, 1998), from a purely economic point of view it would make sense that countries with the highest living standards would attract a disproportional number of migrants, which does not seem to be the case. Certainly, the Scandinavian countries offer among the highest standards of living and the best material conditions in the world, while the available material does not seem to indicate that migrants are overwhelmingly attracted to the Scandinavian countries (Bengtsson, Lundh, and Scott, 2005). In the current state of research, there is no clear-cut answer to the question why migrants seem to prefer some countries over others: "At present, there is no single theory widely accepted by social scientists to account for the emergence and perpetuation of international migration throughout the world, only a fragmented set of theories that have developed largely in isolation from one another" (Massey et al., 1998:17).

Migration always involves two distinct decisions: migrants leave their country of origin but they also have to decide in which host country they want to settle. Push factors have been investigated quite extensively and our knowledge on why migrants decide to leave their country of origin is well developed (Hatton and Williamson, 1994, 1998). This, however, still leaves open the question why migrants are attracted to a specific country. We know by now migrants leave their country mainly because of economic reasons, and they expect better living conditions elsewhere, but this still leaves unresolved the question why they decide to move to country A instead of to country B.

Building on previous analyses, in this article we concentrate on the pull factors: what attracts migration to European countries? We can distinguish at least three possible approaches to explain the pull factors determining a country's attractiveness for migrants. Economic and labor theories assume that migrants react to shortages in the labor market, thus providing for an equilibrium in labor markets, both in their country of origin and in the country they head to. Cultural and world system theory assumes that migration patterns reflect center/periphery relations in the world system. Migrants typically move from the periphery to the center, in terms of linguistic dominance or cultural hegemony. A third, social capital or social network approach basically assumes that migrants are attracted by the fact that other migrants from the same ethnic group have already settled in the receiving society, thus allowing for the occurrence of networks of recruitment (Massey et al., 1998). 
Each one of these theories has been used in contemporary research on migration patterns. In the current article, however, we want to reach a better understanding of the validity of these theoretical approaches by taking two additional steps in the analysis. First, we use a broad comparative data set of migration patterns, covering 21 European countries. Our scope, therefore, is much broader than in earlier research efforts that have tended to concentrate on just one specific ethnic group or one country for a more limited time period. Using such a broad data set provides us with a sufficient number of observations to develop a robust multivariate and multilevel test for these competing theories. Second, we build various models to explain migration flows over a 25year period, thus reducing the risk that our observations would be influenced by temporary or transitory phenomena.

In this article, we first give a review of the hypotheses that have been put forward to explain the pull factors in migration patterns. Subsequently, we present the data and methods that we will use to test the hypotheses we can derive from this literature. In the subsequent sections, we elaborate on the economic, cultural, and network explanations of migration patterns.

\section{LITERATURE REVIEW}

Overviews of the literature on the causes of international migration invariably start with the presentation of the "push-pull framework," which has its origins in liberal economic theories, some of them dating back to the late nineteenth century (Castles and Miller, 1994:19). These theories focus on economic factors to explain migration as they assume that the supply and demand effect (at the macro level) and individual cost-benefit analyses (at the micro level) eventually lead to the establishment of an equilibrium on the labor market, reached by the aggregate effect of individual decisions to migrate to another country. These theories typically lead to the conclusion that people migrate from low income to high income economies, or from regions experiencing a downward economic trend to regions experiencing economic expansion (Borjas, 1995).

These traditional push-pull theories have been subject to much criticism, often due precisely to their association with economic theory, which has come to be perceived as too narrow a focus on a complex phenomenon such as migration. Critics would argue that the concepts were developed in an industrial era, and as such, they no longer offer the best perspective on migration in a postindustrial, globalizing world (Massey et al., 1998:12). From an empirical perspective, too, it has been ascertained that people leaving their country do not 
typically originate from the poorest countries, as cost-benefit approaches would suggest, but rather from regions undergoing rapid social and economic change (Castles and Miller, 1994:22). Moreover, traditional push-pull theories fail to provide a sound explanation for between-country differences, for differences between individuals - i.e., the microstructural causes of migration - and for the resilience of certain flows whose original causes have disappeared or diminished (Portes and Böröcz, 1989:607, 612).

Another more recently developed strand of theories situates migration in a broader context than that of a transfer of people between two nation-states. For instance, according to world systems theory, which developed out of historical-structural theory, migrant flows are triggered when capitalist economic relations enter non- or pre-capitalist societies. Various types of links are created between core capitalist countries and countries situated in the periphery of this core. Among these links enduring cultural ties are of crucial importance, such as the vestiges of colonization in the organization of the education system in former colonies (Massey et al., 1998:40), which is one of the factors that contribute to the attraction of former colonial subjects to their former colonizer.

Portes and Rumbaut (1996:273), too, situate migration in a context of structural unbalancing of peripheral societies under the influence of core capitalist countries, as described in various versions of the world system theory. Apart from historical causes such as occupation, colonization, or active recruitment of foreign laborers, this kind of structural unbalancing may also be brought about by means of mass communication, which spreads information on Western lifestyle and shapes consumption expectations in the culturally peripheral societies.

Whereas the theories discussed so far aim to identify what initially attracts migrants to their destination countries, other theories have been developed to explain why migration flows may become persistent once they have been initiated.

These theories generally focus on networks linking migrants to a variety of people, both migrants and nonmigrants, in their society of origin and at their destination. Such migration-facilitating networks tend to enlarge over time, reducing the costs and risks of migration for ever-greater numbers of migrants. At the same time, migration becomes institutionalized through the workings of various private and voluntary organizations active in the field (Castles and Miller, 1994:25; Massey et al., 1998:448ff). In this way, migration may become the norm rather than the exception for the people within the networks: "To the extent that migration abroad fulfils the goals of individuals and families, the process continues to the point that it becomes normative" (Portes 
and Rumbaut, 1996:276). In this way, migrant flows may be perpetuated despite the disappearance of their initial causes.

Given the empirical nature of this article, we do not feel the need to express a preference for any one of these approaches as our purpose is indeed to explore the empirical validity of each one of these theoretical frameworks. As Massey et al. (1998:12) point out, the traditional push-pull framework provides a categorization of migrations and of factors that play a part in migration, but it does not constitute a theory per se. Therefore, the concept of push and pull factors is not necessarily associated exclusively with liberal economic theory; push and pull factors can be discerned in other theories as well. Furthermore, Massey et al. (1998) argue that these various theoretical approaches do not exclude one another, and they do not necessarily contradict one another. It is also striking to observe that these theoretical approaches do not even mention the role of the state, which would lead to the implicit assumption that political authorities do not really have an impact on the migration patterns into their country.

This theoretical literature does, however, provide us with a set of testable hypotheses on the causes and characteristics of international migration (Massey et al., 1998:50). In the remainder of this article, we want to test these three hypotheses, mainly relying on the OECD and Eurostat data set with regard to international migration patterns. We will also include a number of political control variables, to ascertain whether political systems actually have an impact on immigration patterns and figures.

\section{HYPOTHESES}

The review of the literature in the previous section leads to the formulation of a number of specific hypotheses about the effects of pull factors that could be responsible for a country's attractiveness to migrants.

Economic theory is most straightforward: it is assumed that migrants will respond to incentives operating within the labor market. Perceived shortages of skilled or unskilled labor will lead to the influx of new worker groups. In this view, migration is mainly seen as a mechanism to balance supply and demand on the labor market (DaVanzo, 1978; Borjas, 1995; Feld, 2005). This hypothesis can be operationalized by investigating the relation between various economic indicators (economic growth, income, income/capita, unemployment, etc.) and the influx of migrants into the country (Borjas, 1989; Stark, 1991). An additional research question in this approach is how efficient migration is in achieving an equilibrium in the labor market. Typically we could assume 
that there will be a time lag between the shortage on the labor market and the influx of new migrants. If migration is an efficient mechanism, this time lag could be very short, while a longer time lag could be considered an indicator for inefficiency.

The world system theory paradigm, on the other hand, stresses the role of cultural elements. Here it is assumed that migrants will tend to move from peripheral to central countries. In this approach, migration is seen as a form of cultural hegemony and Massey et al. state that this paradigm leads to the hypothesis:

International migration is especially likely between past colonial powers and their
former colonies, because cultural, linguistic, administrative, investment, transporta-
tion, and communication links were established early and were allowed to develop
free from outside competition during the colonial era, leading to the formation of spe-
cific transnational markets and cultural systems. (1998:41)

This hypothesis can be operationalized by ascertaining whether the former colonial powers still attract migrants mainly from their former colonies, or whether this pull effect tends to diminish over time now that most former colonies are independent for at least four decades.

Finally the social networks explanation stresses the effect of chain migration. Once ethnic communities will have settled in a host country, for whatever reason, this allows future cohorts of this community to gain easier entrance. Often these new arrivals will be attracted by the presence of family members or other networks, offering them various resources in the new society. In the literature, however, there is some disagreement about the question how extended this phenomenon really is (Krissman, 2005). This view can be summarized in the hypothesis:

The size of the migratory flow between two countries is not strongly correlated to
wage differentials or employment rates, because whatever effects these variables have
in promoting or inhibiting migration are progressively overshadowed by the falling
costs and risks of movement stemming from the growth of migrant networks over
time. (Massey et al., 1998:45)

This hypothesis leads to the rather straightforward claim that once an ethnic community has settled in a host country, this will lead to a continuation of this migration pattern. As we will observe later on, however, this hypothesis is most difficult to test with the currently available figures. While economic and cultural pull factors tend to be universal, and they tend to attract people from different countries, the network effect is of course a very specific pull factor which only exerts an influence on people from that one specific ethnic group, not on others. 
In our analysis we will also include a number of control variables to assess the impact of historical and political circumstances. To operationalize the democratic character of a country we included the score of every country on the Freedom House Index, and whether or not the country has implemented any legislation to combat discrimination. Not all countries, however, have open policies toward immigration (Stalker, 2002). To operationalize openness, we included information on whether the country allows non-EU-citizens the right to vote, the length of required stay on the territory in order to be granted citizenship status, and whether or not the country has ever implemented a policy of regularization. Finally, since not all countries have the same capacity to implement their policy, we also included the score on the corruption perception index of Transparency International. The assumption is that countries with high rates of (perceived) corruption will find it harder to effectively control migration toward their country.

\section{DATA AND METHODS}

Despite various efforts to reach standardization and to increase comparability, it remains notoriously difficult to obtain reliable and comparable statistics on migration movements (Lemaitre, 2005). The reason is that every country uses its own procedures to identify immigrants, with varying rules on, e.g., length of residence and legal status. ${ }^{2}$ Since the 1980s, however, the OECD has been strongly involved in the collection of statistics on the international flow of migration. Originally this data collection effort was inspired mainly by the OECD focus on the functioning of the labor market, but since then the data collection has expanded its scope to a more encompassing form of registration. In any case, OECD figures are the only available data set offering a wealth of comparative data on migration toward Europe during the final two decades of the twentieth century. While we fully realize these data are not always as reliable as we would like them to be, we do believe that the wide scope of the data set offers a competitive advantage, compared to some other studies that have focused on just one country, or on a limited numbers of years. The OECD data set, on the other hand, allows us to reconstruct the migration toward all highly industrialized countries, for every year between 1980 and 2004. Although we

${ }^{2}$ Throughout this article, we only refer to legal forms of migration, since this is the only form of migration on which any kind of comparable data are available. Undocumented migration probably is an increasingly important form of immigration, but this form of migration remains completely outside the scope of this article. 
have to admit that at the onset of this research project we shared some of the reservations with regard to the quality of the OECD data, we also decided that, in the end, the proof of the pudding is in the eating. If our analysis would show that there are distinct patterns that can be correlated in a significant manner, e.g., with macroeconomic data, this would be a finding of interest. This would not necessarily mean of course that the OECD data are sufficiently valid, but at least we could assume that the margin of error tends to be stable across countries and across time. If the errors would be completely random and changing over time, this would almost automatically imply that we would not be able to detect stable explanatory patterns.

It has to be stressed in this respect that the OECD data only cover legal migration. Our analysis, therefore, is only valid for legal migration. Selfevidently, we do know that various governments have expressed concern about what they perceive as the rise in illegal immigration into European countries. Figures on illegal immigration, however, can only be estimates, and they are not the result of any official recordings (Cornelius et al., 2004). As such, we did not consider it wise to include these estimates in our statistical analysis.

It also has to be mentioned here that the OECD data set is not exactly user-friendly for this kind of analysis. The older data are available only in printed format, and had to be inputted in a data set manually. Nevertheless, we succeeded in building a data set, which contains, for almost all OECD Member States and for almost every year between 1980 and 2004, figures on:

- $\quad$ the stock of foreigners within the country;

- the total number of foreigners arriving in the country during that year, divided across the country of origin. Where data were missing, we could rely in some instances on figures from Eurostat, the statistical office of the European Union. This massive data set therefore allows us to investigate the various hypotheses we have set out in the preceding sections.

\section{A LOOK AT THE FIGURES}

There can be little doubt that migration toward the industrialized countries in Western Europe is an increasingly important phenomenon (Table 1). Table 1 shows that, in the last two decades, Europe has encountered an increasing inflow of immigrants: from 1980 to 1990, Europe received, each year, about 1.1 million immigrants while this number increased to an average of about 2 million between 1991 and 2004. To summarize it roughly: the number of immigrants Europe receives on average rises by $84,000 /$ year. This observed rise 
TABLE 1

Migration Trends in OECD European Member Countries

\begin{tabular}{|c|c|c|c|c|c|c|}
\hline & \multicolumn{3}{|c|}{ Stock Foreign Population } & \multicolumn{3}{|c|}{ Inflow Foreign Population } \\
\hline & 1980 & 2004 & $\begin{array}{c}\text { Trend } \\
1980-2004\end{array}$ & $\begin{array}{c}1980-1990 \\
\text { (avg/year) }\end{array}$ & $\begin{array}{c}1991-2004 \\
\text { (avg/year) }\end{array}$ & $\begin{array}{l}\text { Trend annua } \\
\text { evolution }^{\mathrm{d}}\end{array}$ \\
\hline$\overline{\text { Austria }^{c}}$ & 3.82 & 9.59 & +5.77 & - & 81,586 & $+8,046$ \\
\hline Belgium & 8.92 & 8.41 & -0.51 & 40,447 & 59,830 & $+1,470$ \\
\hline Czech Republic & 1.73 & 2.48 & +0.75 & 1,352 & 14,657 & $+1,518$ \\
\hline Denmark & 1.78 & 4.97 & +3.20 & 14,457 & 20,906 & +493 \\
\hline Finland & - & 2.08 & - & 12,618 & 9,857 & -208 \\
\hline France & 6.89 & $5.47^{\mathrm{b}}$ & -1.42 & 64,248 & 102,378 & $+2,777$ \\
\hline Germany* & 5.69 & 8.16 & +2.47 & 515,455 & 748,312 & $+10,767$ \\
\hline Greece $^{c}$ & 1.87 & $6.92^{\mathrm{b}}$ & +5.05 & 36,167 & 30,538 & +15 \\
\hline Hungary & - & 1.40 & - & 8,136 & 16,900 & +808 \\
\hline Ireland $^{c}$ & $2.59^{\mathrm{a}}$ & 5.63 & +3.05 & 21,000 & 27,979 & +565 \\
\hline Italy & 0.37 & $3.89^{\mathrm{c}}$ & +3.51 & 90,364 & 175,899 & $+1,765$ \\
\hline Luxembourg & 24.68 & 39.42 & +14.75 & 7,261 & 10,343 & +231 \\
\hline Netherlands & 3.68 & 4.32 & +0.64 & 55,434 & 79,681 & $+1,559$ \\
\hline Norway & 2.02 & 4.64 & +2.62 & 16,158 & 23,334 & +688 \\
\hline Poland & 0.13 & 0.13 & +0.00 & 1,704 & 16,627 & $+1,248$ \\
\hline Portugal $^{\mathrm{c}}$ & 0.52 & 4.32 & +3.80 & - & 24,842 & $+4,576$ \\
\hline Slovenia ${ }^{c}$ & $0.06^{\mathrm{a}}$ & 2.30 & +2.24 & - & 5,069 & +483 \\
\hline Spain & 0.49 & 4.63 & +4.14 & 21,782 & 185,847 & $+17,696$ \\
\hline Sweden & 5.07 & 5.18 & +0.10 & 36,082 & 43,710 & +640 \\
\hline Switzerland & 4.13 & 20.42 & +6.30 & 72,543 & 91,085 & $+1,095$ \\
\hline United Kingdom & $3.14^{\mathrm{a}}$ & 4.81 & +1.67 & - & 231,585 & $+26,085$ \\
\hline OECD Europe & 3.32 & 5.30 & +1.97 & $1,068,695$ & $2,000,965$ & $+84,130$ \\
\hline
\end{tabular}

Source: OECD, Eurostat, and own calculations by the authors. Stock in percentage of total population; flow in absolute numbers.

*Before 1989 this is the sum of the scores for East and West Germany.

${ }^{\text {aD }}$ ata for 1990 instead of 1980 are used due to missing values.

${ }^{\mathrm{b}}$ Data for 2000 instead of 2002 are used due to missing values.

'Some missing values are present. Averages per year are calculated on the figures for the available inflow statistics.

${ }^{\mathrm{d}}$ Results from an OLS-regression analysis. Virtual annual evolution of the migration inflow to the country (absolute numbers).

in migration inflow can be attributed to almost every European country: except for Finland and Greece, all European countries received significantly more immigrants in the 1990s and the first years of the twenty-first century than in the 1980-1990 period. The increase is strongest in Germany: while that country (East and West combined) received 515,000 immigrants in the 1980s; this was up to 750,000 in the ten years between 1995 and 2004. For the United Kingdom, Spain, and Italy we can also observe substantial increases.

This increasing inflow of immigrants is also reflected in the evolution in the stocks of the foreign population in the different European countries. It has to be remembered here that OECD and Eurostat figures include "foreigners," i.e., inhabitants who are not a citizen of the country. This implies that former immigrants who are naturalized and have received citizenship are no longer 
included in these figures. The official figures on "foreign nationals" are therefore an underestimate of ethnic diversity in general. Even taking into account this limitation, the population of almost every European country has become more ethnically and culturally diverse between 1980 and 2004. The only exceptions here are Belgium and France, and it has to be remembered that in both countries a substantial number of resident foreigners have received citizenship. On average, about 3.3 percent of the population in the European countries in 1980 had foreign citizenship, and this was up to 5.3 percent in 2004. Substantial increases can be found in Luxembourg, Switzerland, Greece, and Austria.

When we plot the figures from Table 1 in Figure I, we can observe that the upward trend in migration flows can be found in all European regions. Since 1990, the countries in Central and Eastern Europe, too, have experienced a rapid rise in the number of immigrants entering the country. Although patterns might vary between countries, the general trend line is clearly up. For recent years, the strongest increase can be found in southern and Eastern Europe.

After this overview, we can now proceed to the test of our hypotheses. First, we test the economic theory, followed by a test of the theory of cultural hegemony and, finally, a test of the network theory.

\section{TESTING THE ECONOMIC HYPOTHESES}

Ideally, we wanted to test all of our hypotheses simultaneously to assess and compare their validity. One has to remember, however, that our data set only provides us with information on 21 cases or countries. This implies that the number of independent variables that we can enter simultaneously will have to be limited. Therefore, we gradually build our model by running separate models for each of the three approaches we listed in our theoretical section. Subsequently, we focus on the variables that proved to be significant in the economic, cultural, or network models and we include all of these variables in our final model.

In this analysis, the dependent variable is the immigration flow into the country, for the years between 1980 and 2004. Each inflow figure (the number of people entering a specific country in a specific year) is seen as a separate observation. This leaves us with 426 observations in total. However, these 426 observations are not independent, since they are clustered within 21 countries. As we have seen in Table 1, at least some similarity between inflows into one and the same country is present. The inflow figures for Germany or the UK, for 
Figure I. Migration Flows to European Countries 1980-2004
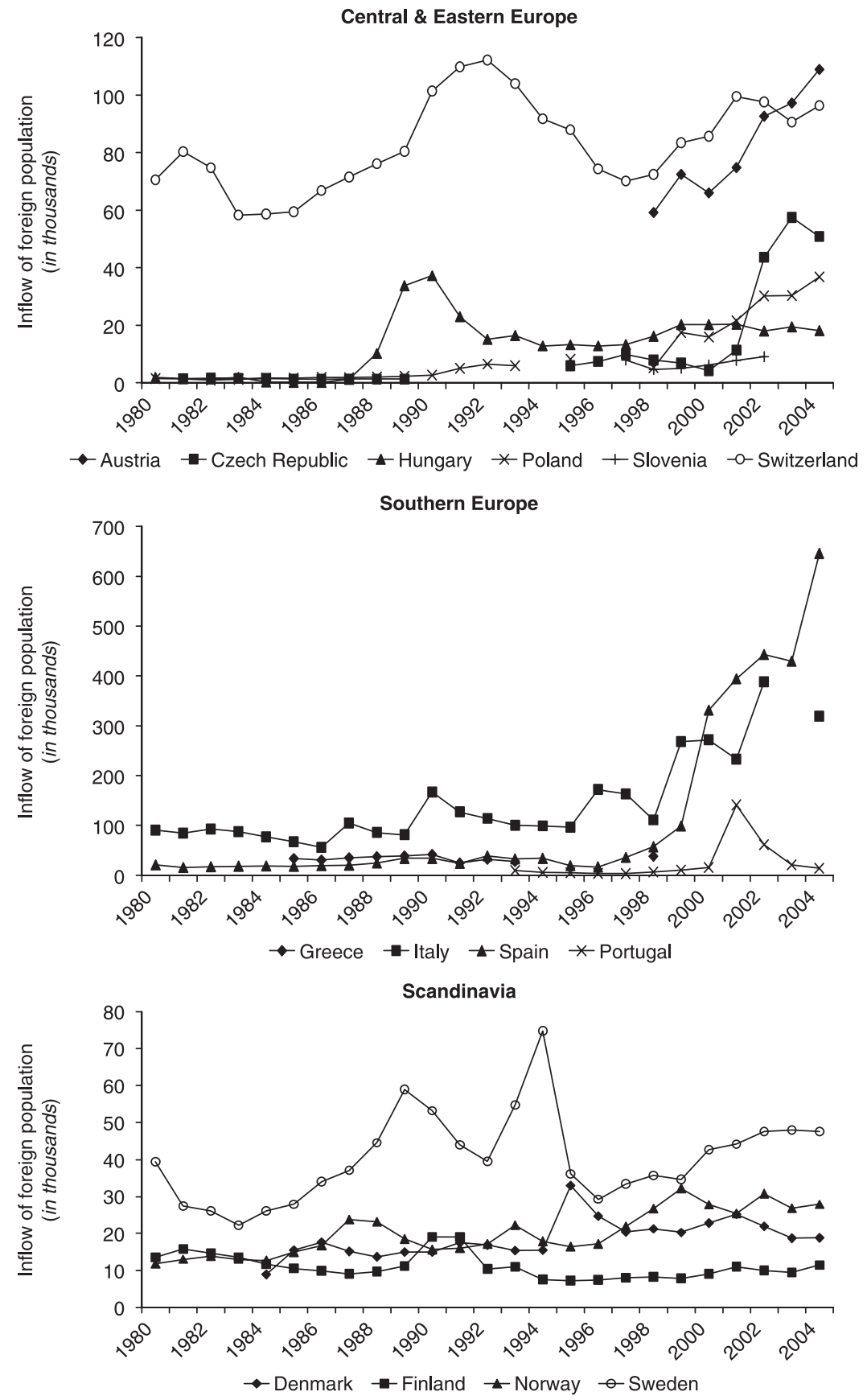
Figure I. (Continued)
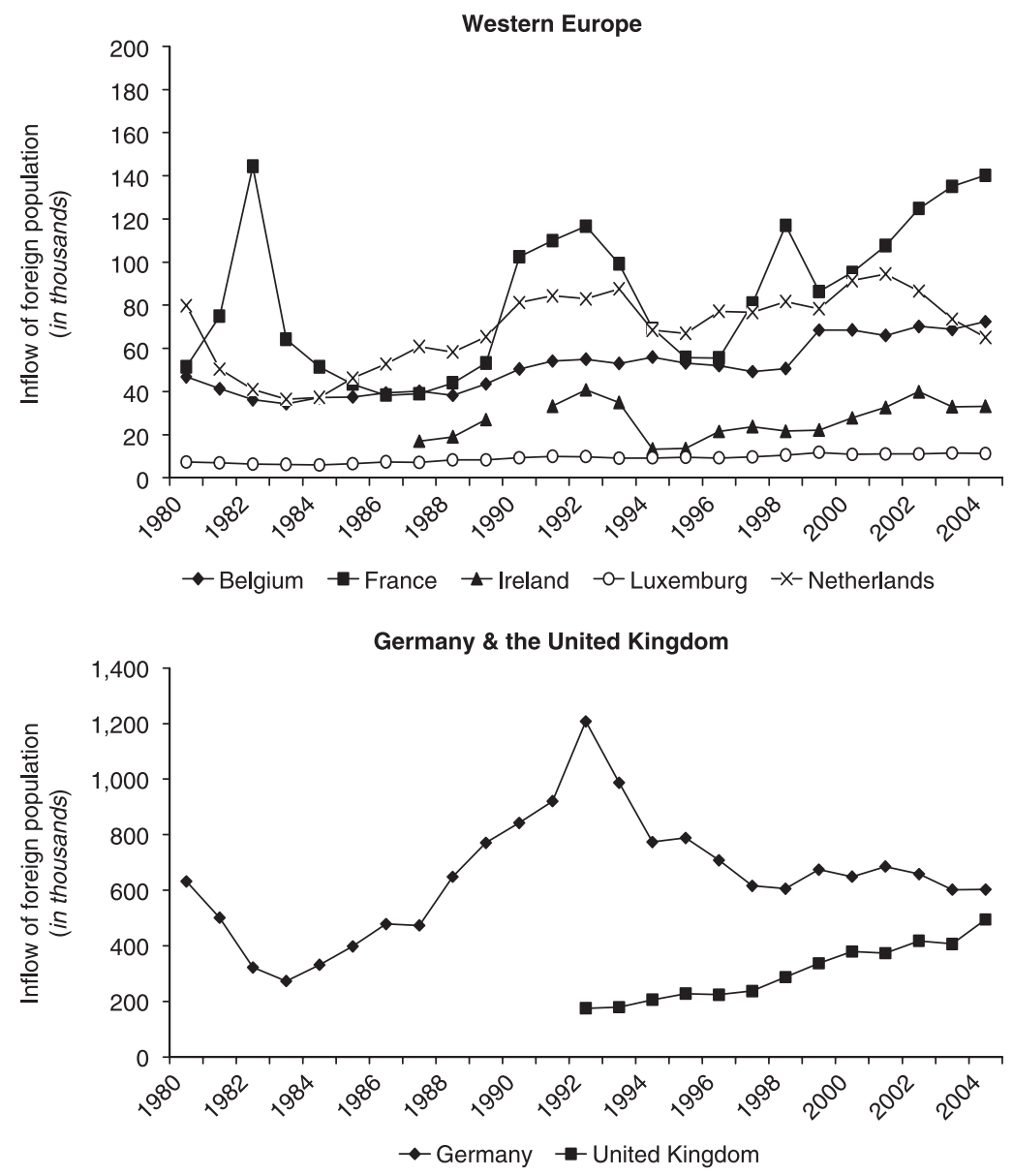

Source: OECD and Eurostat, 1980-2004, and own calculations by the authors.

example, are systematically higher than those for countries such as Luxemburg or Slovenia. Standard statistical techniques, such as multivariate regression analysis, are not appropriate to analyze this kind of clustered data. Given the nested or clustered structure of the data set, we have to use general linear mixed modeling (Verbeke and Molenberghs, 2000). This statistical method renders it possible to distinguish different levels of analysis: in this case we can make a distinction between level I effects (the year within the country series) and level II effects (the country, which serves as a higher level). Technically, this 
differentiation between the two levels is obtained by specifying so-called random effects, such as country-specific intercepts or slopes. Furthermore, the observations within a country are not considered as having a random order. Instead, they are modeled as an evolution over time, by including a timevariable, indicating the year of the observation.

In each one of the following models, we included a number of basic control variables. First of all, a time effect was applied to control for the fact that we are dealing with time series. As immigration flows have shown not to evolve in a linear way, a quadratic time effect $\left(\right.$ time $\left.^{2}\right)$ was included as well. Because the data show that the evolution of immigration strongly differs from one region to another, these time effects were allowed to vary over the countries (by means of random slopes for time and time $^{2}$ ). Furthermore, we also included the population figure of the host country (population host country) to control for the simple fact that large countries will attract a larger number of migrants than small countries.

In all models, both dependent and independent variables were standardized before the analysis. By consequence, the reported parameters can be interpreted as standardized parameters, i.e., they can be compared in magnitude.

In our first model, we test the economic explanation for the attractiveness of a country. In this model we try to predict the migration flow by using the following independent variables:

- $\quad$ unemployment rate: percentage of the active population that is registered as unemployed;

- $\quad$ economic growth: real GDP growth (percentage change on the previous year);

- GDP per capita, as an indicator for the wealth of a country;

- $\quad$ total social expenditure (in percentage of GDP).

All of these measurements could be obtained from the OECD economic data sets. For the first two indicators, figures are available for separate years in our time range. As we also wanted to detect how efficient migration patterns react to changing economic circumstances, we experimented with various time lags in our models, e.g., using unemployment rates from the same year as the observation $(\mathrm{t})$, one year earlier $(\mathrm{t}-1)$, and so on. For the final two variables the information in the OECD data sets is less complete, so that averages over 5- (social expenditure) or 10-year time periods (GDP per capita) had to be included in the model. Despite the fact that we also searched in other international comparative economic data sets, we did not succeed in obtaining 
TABLE 2

An Economic Explanation for Migration Flows to Europe

\begin{tabular}{|c|c|c|c|c|}
\hline Fixed Effects & Estimate & SE & t-value & p-value \\
\hline Intercept & -0.055 & 0.141 & -0.39 & 0.7000 \\
\hline Time & -0.208 & 0.160 & -1.30 & 0.2097 \\
\hline Time $^{2}$ & 0.369 & 0.190 & 1.94 & 0.0683 \\
\hline Population host country & 0.861 & 0.166 & 5.17 & $<.0001$ \\
\hline GDP per capita & -0.044 & 0.045 & -0.98 & 0.3273 \\
\hline Social expenditure & 0.080 & 0.048 & 1.68 & 0.0953 \\
\hline Unemployment $\mathrm{t}-1$ & -0.131 & 0.061 & -2.15 & 0.0327 \\
\hline Real GDP growth $\mathrm{t}-2$ & 0.012 & 0.016 & 0.79 & 0.4279 \\
\hline Random Effects & Estimate & SE & Z-value & p-value \\
\hline Variance random intercept & 0.366 & 0.132 & 2.78 & 0.0028 \\
\hline Variance random slope time & 0.381 & 0.153 & 2.50 & 0.0063 \\
\hline Variance random slope time ${ }^{2}$ & 0.607 & 0.227 & 2.68 & 0.0037 \\
\hline Residual variance & 0.021 & 0.002 & 9.83 & $<.0001$ \\
\hline
\end{tabular}

Note: Entries are results from a general linear mixed model for 1980-2004 immigration flows to European countries. $\mathrm{N}=275$.

information for every country/year combination. Especially for the 1980s, reliable economic statistics, e.g., for Eastern Europe, proved to be a problem. Therefore, only 275 of the initial 426 observations could be used to test the economic explanation.

Table 2 summarizes the result of the economic explanatory model. First of all, we have a look at the effects of the basic control variables. The quadratic time effect is rather hard to interpret, because country-specific deviations were allowed by specifying random slopes for these variables. As could be expected, the population figure of the host country is one of the main determinants of the influx of immigrants. Obviously, countries with a large number of inhabitants - thus, larger countries - attract more immigrants.

The results in Table 2 show that most hypotheses derived from the literature on economic explanations for migration are not confirmed in this analysis. Gross domestic product/capita is not significantly related to the influx of migrants, indicating that migrants do not systematically select the richest countries among the OECD member states. Neither is there a significant relation with the percentage of social expenditure, indicating that migrants do not select countries with a generous social security regime. Unemployment is the only variable with a significant impact. The effect is negative: low unemployment figures seem to attract migrants, and thus migration indeed primarily seems to function as a mechanism to restore imbalances in the labor market. Economic growth does not seem to be related to immigration figures. As we will see later, however, the absence of a significant effect for economic growth 
TABLE 3

Standardized Effect Parameter for Unemployment with Different Time Lags

\begin{tabular}{lcccc}
\hline \hline & Estimate & SE & t-value & p-value \\
\hline Unemployment t & -0.049 & 0.023 & -2.16 & 0.0322 \\
Unemployment t -1 & -0.085 & 0.041 & -2.11 & 0.0367 \\
Unemployment $\mathrm{t}-2$ & -0.066 & 0.033 & -2.01 & 0.0455 \\
Unemployment $\mathrm{t}-3$ & -0.038 & 0.025 & -1.53 & 0.1286 \\
Unemployment $\mathrm{t}-5$ & 0.019 & 0.022 & 0.87 & 0.3869 \\
\hline
\end{tabular}

Note: Entries are results from a general linear mixed model for 1980-2004 immigration flows to European countries. Five different models, like Table 2, are included. In this table we report only the various unemployment variables; all other results are not repeated.

is due to the high (negative) correlation with unemployment. If unemployment is dropped from the model, economic growth turns out to coincide significantly with higher levels of immigration. Overall, however, unemployment is a better explanatory variable than economic growth.

The estimates of the random effects show that the largest part of the total variance can be attributed to the country level. In other words: the differences between countries are larger than the fluctuations over time within countries. The random slopes for both time and time ${ }^{2}$ are significant, which indicates that the evolutions over time vary across countries.

The model reported in Table 2 accounts for $36.2 \%$ of the variance across time within countries (level I) and for $36.9 \%$ of the variance between the countries (level II). ${ }^{3}$ It has to be acknowledged, however, that the largest part of the explanatory power is derived from the control variables (the quadratic time effect and the population figure of the host country).

In Table 2, we included the unemployment figures of the year just prior to the observation of the immigrant flow $(t-1)$. We did so after testing various time lags in the model (Table 3). Table 3 reports the values for the unemployment variable in comparable models as the one reported in Table 2. For reasons of clarity, all the other variables included in our model are not repeated here. Based on the size of the standardized parameter, we conclude that unemployment gives the best prediction of migration flows if the time lag is 1 year. The observations for $\mathrm{t}$ (the same year) or $\mathrm{t}-2$ one would also be significant, but $\mathrm{t}-1$ results in the strongest estimate.

\footnotetext{
${ }^{3}$ The proportional reduction of the mean squared error of prediction at both levels was used as a measure for the explained variance $\left(\mathrm{R}^{2}\right)$. This mean squared error of prediction can be calculated as $\sigma^{2}+\tau^{2}$ (level I) and $\sigma^{2}+\tau^{2} / n$ (level II or country level), where $\sigma^{2}$ is the residual variance, $\tau^{2}$ the variance of the random intercept and $n$ the harmonic mean of the group sizes. As Snijders and Bosker (1994) suggest, the presence of random slopes was not taken into consideration in the calculation of the explained variance.
} 
TABLE 4

Standardized Effect Parameters for Economic Growth with Different Time Lags

\begin{tabular}{lccrr}
\hline \hline & Estimate & SE & t-value & p-value \\
\hline Real GDP growth t & -0.016 & 0.008 & -1.94 & 0.0535 \\
Real GDP growth t -1 & 0.008 & 0.006 & 1.36 & 0.1747 \\
Real GDP growth $\mathrm{t}-2$ & 0.027 & 0.013 & 2.00 & 0.0464 \\
Real GDP growth $\mathrm{t}-3$ & 0.022 & 0.012 & 1.79 & 0.0750 \\
Real GDP growth $\mathrm{t}-5$ & 0.022 & 0.016 & 1.37 & 0.1721 \\
\hline
\end{tabular}

Note: Entries are results from a general linear mixed model for 1980-2004 immigration flows to European countries. Five different models, like Table 2, are included. In this table we report only the various GDP growth variables; all other results are not repeated.

This comparison shows that migration is not just a powerful, but also a rather efficient, mechanism to restore imbalances on the labor market. After one year only, migration flows react to signals from the labor market. It falls out of the scope of this article to determine the exact causal mechanism responsible for this effect. It might be that potential immigrants are specifically attracted by all kinds of job offers; another possible explanation is that government agencies become more lenient in their admission procedures and decisions when there is a shortage on the labor market. Self-evidently a combination of both factors is also possible, but for the moment we can reserve this for future research.

A similar analysis was performed to determine the optimal time lag for the variable "real GDP growth." Here, a time lag of two years leads to the best results (Table 4). Given the literature on economic cycles, it seems plausible that the time lag for GDP growth is larger than for unemployment. In an economic growth cycle, we first observe a rise in GDP figures; this is followed by shortages on the labor market, and in a next phase this leads to attracting new immigrants. Again, however, determining exact causal mechanisms falls outside of the scope of this article.

To summarize, the economic analysis did not reveal any significant effects for GDP/capita, evolution in GDP, or social expenditure in the host country. It did reveal, however, that migration patterns respond to increased demands on the labor market, with a reaction time or time lag of approximately one year.

\section{TESTING THE WORLD SYSTEM APPROACH: COLONIAL PAST}

Subsequently, we turn to our effort to test the cultural theories on immigration. First, we operationalized the "center/periphery" approach in a rather 
TABLE 5

A Cultural Explanation for Migration Flows

\begin{tabular}{|c|c|c|c|c|}
\hline Fixed Effects & Estimate & SE & t-value & $p$-value \\
\hline Intercept & -0.053 & 0.171 & -0.31 & 0.8289 \\
\hline Time & -0.005 & 0.167 & -0.03 & 0.9744 \\
\hline Time $^{2}$ & 0.151 & 0.189 & 0.80 & 0.4354 \\
\hline Population host country & 0.057 & 0.028 & 2.06 & 0.0399 \\
\hline Distance to equator & -0.002 & 0.032 & -0.07 & 0.9444 \\
\hline Pop. former colonies & 0.195 & 0.068 & 2.89 & 0.0041 \\
\hline Random effects & Estimate & SE & $t$-value & $\mathrm{p}$-value \\
\hline Variance random intercept & 0.644 & 0.214 & 3.02 & 0.001 \\
\hline Variance random slope time & 0.544 & 0.189 & 2.87 & 0.002 \\
\hline Variance random slope time ${ }^{2}$ & 0.704 & 0.241 & 2.92 & 0.002 \\
\hline Residual variance & 0.081 & 0.006 & 13.64 & $<.0001$ \\
\hline
\end{tabular}

Note: Entries are results from a general linear mixed model for 1980-2004 immigration flows to European countries. $\mathrm{N}=426$.

straightforward manner, by simply calculating the distance to the equator of the host country. If we assume that migrants typically arrive in Europe from southern countries that can be considered economically peripheral, we might assume that their first "port of arrival" will be the Southern European countries. In this cultural approach, however, the stress is on cultural domination, which is expressed by the former colonial ties. As an independent variable, we therefore included the total number of inhabitants of the former colonies of the host country. For most European countries this figure is 0 , but there are also countries with huge former colonial empires. All former British colonies combined now have 1,980,000,000 inhabitants (figures for 2005), for France this is 272,000,000; for Portugal 223,000,000, and for Belgium $79,000,000$ inhabitants. If the cultural explanation is correct, we might assume that the former colonial powers will still attract migrants from their former colonies. Table 5 is constructed in the same manner as Table 2: time, time ${ }^{2}$, and the population of the host country are included as control variables. Unlike our economic analysis, this model is not plagued by missing values, so we can use all 426 observations.

As the results in Table 5 indicate, the distance from a country to the equator does not influence the inflow of migrants. The colonial past of a country, on the other hand, seems to play an important role in contemporary migration fluxes. This finding supports the cultural approach: the more inhabitants in the former colonies of a country, the larger the immigration flows that country receives. This effect is even highly significant. This cultural model explains 22.4 
percent of the evolutions over time (level I) and 24.4 percent of the differences between countries (level II). ${ }^{4}$

Table 5 indicates that the former colonial powers still attract a substantial number of immigrants. It has to be remembered that our data cover the entire 1980-2004 time period. While we could expect that the colonial past still makes a difference in the early 1980s, one wonders whether this effect is still as powerful in the current, increasingly globalizing world. This question can be answered by specifying an interaction term between time and the variable "population of former colonies." When using this variable, however, it has to be remembered that the British Commonwealth, by itself, accounts for about one-third of the entire world population, which is much higher than that of any of the other colonial empires. Furthermore, the United Kingdom is notorious for the fact that its immigration statistics do no always live up to European standards. To account for this obvious outlier, we conducted the analysis, first using all observations $(n=426)$, and second omitting the UK $(n=413)$. In our first model, we simply confirm the fact that the number of inhabitants of the former colonies has a significant effect on the current number of immigrants entering the country. When we subsequently also include an interaction effect, this also exerts a significant effect. This indicates that, all countries combined, the effect of the colonial past still seems to be rising.

However, in the final columns of Table 6 we repeat exactly the same models, this time omitting the UK observations. The simple model again confirms the importance of the number of inhabitants of the former colonies. It is quite remarkable to observe that this variable remains highly significant, even after removing the 2 billion inhabitants of the British Commonwealth from our analysis. When we subsequently also include the interaction with time, we see remarkable differences. The interaction term is not significant in this model, indicating that if we do not take into consideration the United Kingdom, the impact of the former colonial past does not seem to increase over time. Our initial observation of the influence of the colonial past, therefore, can

\footnotetext{
${ }^{4}$ The proportions of explained variance of the economic and cultural models should not be compared directly, because the number of observations in this second model is substantially larger than in the first model. It is also worth noting that in this cultural model the population of the host country has a much smaller effect than in the previous economic model. Here, too, the different number of observations is responsible for the difference. In the economic model we mainly had to exclude Eastern European countries for the 1980s, due to missing economic data. These are precisely the years and countries where the ratio "immigration/population of host country" is small. Therefore, the effect of the population figure of the host country was overestimated in the economic model.
} 
TABLE 6

Cultural Explanation Models, with and without UK

\begin{tabular}{|c|c|c|c|c|c|c|c|c|}
\hline \multirow[b]{3}{*}{ Fixed Effects } & \multicolumn{8}{|c|}{ Model without Interaction } \\
\hline & \multicolumn{4}{|c|}{ All Countries $(\mathrm{N}=426)$} & \multicolumn{4}{|c|}{ Without the UK $(\mathrm{N}=413)$} \\
\hline & Estimate & SE & $\mathrm{t}$-value & $\overline{\mathrm{p} \text {-value }}$ & Estimate & SE & $\mathrm{t}$-value & p-value \\
\hline Intercept & -0.053 & 0.171 & -0.31 & 0.7597 & -0.052 & 0.177 & -0.30 & 0.7709 \\
\hline Time & -0.005 & 0.167 & -0.03 & 0.9752 & 0.040 & 0.168 & 0.24 & 0.8162 \\
\hline Time & 0.150 & 0.189 & 0.80 & 0.4354 & 0.087 & 0.187 & 0.47 & 0.6472 \\
\hline Population host count & 0.058 & 0.016 & 3.68 & 0.0003 & 0.061 & 0.015 & 4.04 & $<.0001$ \\
\hline \multirow[t]{3}{*}{ Pop. former colonies } & 0.194 & 0.051 & 3.80 & 0.0002 & 0.168 & 0.063 & 2.68 & 0.0078 \\
\hline & \multicolumn{8}{|c|}{ Model with Interaction Effect } \\
\hline & \multicolumn{4}{|c|}{ All countries $(\mathrm{N}=426)$} & \multicolumn{4}{|c|}{ Without the UK $(\mathrm{N}=413)$} \\
\hline Fixed Effects & Estimate & SE & $\mathrm{t}$-value & p-value & Estimate & SE & t-value & $\overline{p \text {-value }}$ \\
\hline Intercept & -0.065 & 0.175 & -0.37 & 0.7125 & 0.075 & 0.199 & 0.38 & 0.7096 \\
\hline Time & 0.000 & 0.168 & 0.00 & 0.9996 & 0.080 & 0.155 & 0.52 & 0.6116 \\
\hline Time & 0.143 & 0.185 & 0.77 & 0.4476 & 0.085 & 0.185 & 0.46 & 0.6504 \\
\hline Population host country & 0.074 & 0.015 & 4.84 & $<.0001$ & 0.062 & 0.015 & 4.14 & $<.0001$ \\
\hline Pop. former colonies & 0.313 & 0.050 & 6.28 & $<.0001$ & 0.863 & 0.597 & 1.45 & 0.1489 \\
\hline Time x pop. former colonies & 0.066 & 0.014 & 4.65 & $<.0001$ & 0.215 & 0.183 & 1.18 & 0.2398 \\
\hline
\end{tabular}

Note: Entries are results from a general linear mixed model for 1980-2004 immigration flows to European countries.

be attributed completely to the United Kingdom and its huge former colonial empire. It has to be remembered however, that this implies that the impact of the colonial past does not significantly change over time; it simply seems to remain stable and it does not diminish or increase significantly.

The analysis reported in Tables 5 and 6, however, only covers general immigration patterns. We see that the former colonial powers still attract a significantly larger number of immigrants. We do not know, however, whether these immigrants are indeed originating from the former colonies. A stricter test, therefore, is that for each one of the former colonial powers we can calculate the proportion of immigrants originating from the former colonies. That way we can ascertain in a more direct manner whether the colonial heritage becomes more or less important in explaining immigration patterns and attractiveness to immigrants (Table 7).

We can observe that in the 1980s more than half of all immigrants in the United Kingdom actually originated from the Commonwealth countries. In recent years, this proportion has declined, and in the most recent figures, about a quarter of all UK immigrants still originate from the former colonies. In the Netherlands, too, we can observe that the importance of the former colonies (Suriname and Indonesia) has declined substantially in recent decades. In France and Southern Europe, however, we can observe exactly the opposite 
TABLE 7

INFLOW FROM Former COLONIES

\begin{tabular}{lccccccc}
\hline \hline Year & UK & France & Spain & Portugal & Italy & Belgium & Netherlands \\
\hline 1980 & - & 34.44 & - & - & - & - & - \\
1981 & - & 35.60 & - & - & - & - & 6.35 \\
1982 & 60.07 & 37.88 & - & - & - & - & 4.89 \\
1983 & 54.92 & 32.09 & - & - & - & - & 8.23 \\
1984 & 58.20 & 28.79 & - & - & - & - & 4.56 \\
1985 & 60.66 & 26.50 & - & - & - & - & 6.93 \\
1986 & 59.79 & 27.68 & - & - & - & - & 7.01 \\
1987 & 57.59 & 28.72 & - & - & - & & 7.06 \\
1988 & 56.70 & 31.14 & - & - & - & - & 4.97 \\
1989 & 55.23 & 31.58 & - & - & - & - & 6.73 \\
1990 & 54.85 & 26.21 & - & - & - & 3.50 & 8.36 \\
1991 & 54.92 & 24.31 & - & - & - & 3.45 & 7.91 \\
1992 & 55.93 & 19.29 & - & - & - & 4.89 & 8.29 \\
1993 & 52.70 & 22.85 & - & 18.18 & - & 4.34 & 8.95 \\
1994 & 43.11 & 19.92 & - & 14.04 & - & 3.90 & 4.22 \\
1995 & 51.24 & 34.55 & 21.54 & 14.00 & 3.70 & 1.86 & 2.56 \\
1996 & 30.09 & 33.45 & 19.16 & 8.33 & 12.22 & 1.54 & 2.22 \\
1997 & 27.98 & 36.22 & 16.25 & 9.09 & 9.35 & 1.22 & 3.39 \\
1998 & 31.71 & 34.22 & 19.06 & 23.08 & 10.09 & 1.38 & 3.92 \\
1999 & 26.41 & 35.81 & 26.34 & 20.95 & 13.88 & 1.17 & 2.30 \\
2000 & 21.64 & 38.55 & 47.23 & 23.90 & 11.49 & 1.17 & 2.30 \\
2001 & 28.69 & 33.09 & 44.19 & 17.86 & 11.99 & 2.12 & 2.33 \\
2002 & - & 37.60 & 32.70 & 28.13 & 10.08 & 1.85 & 2.54 \\
2003 & - & 50.42 & 37.11 & 39.52 & - & 1.60 & 3.26 \\
2004 & - & 47.84 & $18.58 b$ & 36.17 & - & 1.52 & 3.07 \\
Trend Annual Evolution ${ }^{\mathrm{a}}$ & -2.04 & +0.43 & +1.58 & +2.15 & +0.64 & -0.21 & -0.23 \\
\hline & & & & & &
\end{tabular}

Notes: Entries are percentage of the total migration inflow originating from a former colony.

${ }^{a}$ Results from an OLS-regression analysis, summarizing annual trends.

trend. In Spain and Portugal the percentage of immigrants arriving from former colonies has even increased substantially. If we compare all the figures, it is clear that we cannot arrive at a simple and unequivocal answer to the question whether or not the importance of the colonial heritage declines. This seems to be the case for the northern countries (UK, the Netherlands), but not for France and the Southern European countries. These contradictory trends explain why, overall, there is no interaction between time and colonial past, and on an aggregate level we observe a stability of the relation. This implies that, almost half a century after decolonization, the former colonial heritage still continues to shape migration patterns to Europe.

WORLD SYSTEM HYPOTHESES: LANGUAGE

The hypotheses derived from world system or hegemony theory, however, might also be operationalized in a slightly different manner. Cultural 
TABLE 8

Effects of Dominance of the Language on Migration

\begin{tabular}{|c|c|c|c|c|}
\hline Fixed Effects & Estimate & SE & $\mathrm{t}$-value & p-value \\
\hline Intercept & -0.022 & 0.189 & -0.12 & 0.9072 \\
\hline Time & 0.014 & 0.190 & 0.07 & 0.9423 \\
\hline Time $^{2}$ & 0.158 & 0.216 & 0.73 & 0.4727 \\
\hline Population host country & 0.125 & 0.016 & 7.60 & $<.0001$ \\
\hline Language & 0.038 & 0.011 & 3.44 & 0.0007 \\
\hline Random effects & Estimate & SE & $\mathrm{t}$-value & p-value \\
\hline Variance random intercept & 0.673 & 0.241 & 2.80 & 0.0026 \\
\hline Variance random slope time & 0.600 & 0.226 & 2.65 & 0.0040 \\
\hline Variance random slope time ${ }^{2}$ & 0.784 & 0.291 & 2.69 & 0.0036 \\
\hline Residual variance & 0.098 & 0.008 & 12.35 & $<.0001$ \\
\hline
\end{tabular}

Note: Entries are results from a general linear mixed model for 1980-2004 immigration flows to European countries. $\mathrm{N}=351$. Belgium, Luxembourg, and Switzerland not included because these countries have more than one official language.

hegemony is expressed not only by the colonial past, but also by language. The center position of the UK, France, and Spain does not refer only to their history, but also to the fact that their official languages are being spoken by a large population in various continents. The number of persons worldwide that (officially) speak a language can be seen as an indicator of the dominance of that particular language. Countries where a dominant language is being spoken (like Spain or France), will attract more immigrants than countries where this is not the case (like Sweden or Poland), according to the cultural approach. To test this hypothesis, the number of persons that officially speak the language of the immigration country was included as an independent variable. Take France as an example: the value of this variable is the sum of the inhabitants of all the countries where French is the major official language. Obviously, there will be a strong correlation between the former colonial past and the current language use. In most former French colonies, French is still the official language, and with regard to English the same holds for most Commonwealth countries. The correlation between the variables "population of the former colonies" and "users of official language" is .55, and this multicollinearity implies that both variables cannot be included simultaneously in the analysis. Therefore, we need a separate model if we want to test the language factor (Table 8).

The analysis shows that European countries whose official language is spoken by a large number of persons outside the country indeed attract a larger number of immigrants. However, the effect of language dominance is smaller than that of the colonial past (Table 6). Therefore, we opt for including colonial ties rather than language dominance in the final model. 


\section{NETWORK APPROACH}

Finally, the network approach predicts that the presence of migrant communities in a settler country or city facilitates further immigration. These ethnic communities make entrance easier for persons coming from their native country, by providing them with useful information or contacts. Over time, this process would lead to chain migration. The network approach will be tested by including the stock of foreign population at the beginning of the decade as an independent variable. ${ }^{5}$ However, a word of caution is in order here. The network approach has to be considered a micro- or meso-level theory: it explains why the settlement of certain ethnic communities shows particular patterns. Our model, on the other hand, is situated at the macrosociological level. So rather than performing a stringent test for the existence of chain migration, the macro-level model will try to grasp a process that essentially takes place at the micro or meso level. It can be argued, however, that if the current stock of immigrants does not seem to have an effect on the subsequent number of immigrants coming in, this implies that the network approach does not offer a good explanation for the total number of immigrants a country receives (macro level). Nevertheless, on a micro or meso level it might still be the case that individual immigrants or groups of immigrants are attracted by the presence of their relatives or acquaintances in the host country. Again, this is outside the scope of the article.

Table 9 indicates that the initial size of the stock of foreigners in the country does not have a bearing on the subsequent number of immigrants. Indeed, as we saw in Table 1, in 1980 Southern and Eastern European countries had a very small stock of foreigners, while in recent years they have become rather popular as settler countries. If migration patterns where only dependent on chain migration, these changes over time would be hard to explain, since immigrants would simply have to continue to go to the countries in which they already have networks available. This is obviously not the case. Again, we have to stress here that various explanatory variables might be at work on various levels. An individual immigrant deciding to settle in, e.g., Poland or the Slovak Republic, might still make this decision based on his or her individual

${ }^{5}$ Given the fact that we mainly rely on OECD data, we have simply adopted the terms used by the OECD itself. "Migrants" or "immigrants" are being used to designate those entering the country; "foreigners" is the term used to designate those officially residing in the country without full citizenship status. To avoid any confusion we thought it was preferable to use exactly the same terms as our data source. 
TABLE 9

A Network Explanation Model

\begin{tabular}{|c|c|c|c|c|}
\hline Fixed Effects & Estimate & SE & t-value & p-value \\
\hline Intercept & -0.010 & 0.171 & -0.06 & 0.9530 \\
\hline Time & 0.002 & 0.177 & 0.01 & 0.9913 \\
\hline Time $^{2}$ & 0.156 & 0.204 & 0.76 & 0.4537 \\
\hline Population host country & 0.123 & 0.015 & 8.17 & $<.0001$ \\
\hline Stock foreign population & 0.002 & 0.004 & 0.42 & 0.6731 \\
\hline Random effects & Estimate & SE & $t$-value & $\mathrm{p}$-value \\
\hline Variance random intercept & 0.606 & 0.203 & 2.98 & 0.0014 \\
\hline Variance random slope time & 0.557 & 0.201 & 2.77 & 0.0028 \\
\hline Variance random slope time ${ }^{2}$ & 0.739 & 0.264 & 2.80 & 0.0026 \\
\hline Residual variance & 0.092 & 0.007 & 12.75 & $<.0001$ \\
\hline
\end{tabular}

Note: Entries are results from a general linear mixed model for 1980-2004 immigration flows to European countries. $\mathrm{N}=426$.

networks. On a macro level, however, the stock of foreign nationals already present in the country does not seem to be a good explanation for the current attractiveness of the country for immigrants.

\section{POLITICAL CONTROL VARIABLES}

Thus far we have not included any political and historical variables in our analysis, and indeed, the theoretical approaches that we want to test in this article could be criticized on the ground that they do not even address the role political systems can play in controlling immigration. Nevertheless, it seems crucial that if we want to arrive at a comprehensive explanation of immigration patterns, we also need to include at least some information on political variables. ${ }^{6}$ As we already mentioned in sections 2 and 3, we included various country-level measurements in the model in order to detect possible influences of policy systems.

Again we proceeded in the same manner as with earlier analyses. Granting voting rights to non-EU nationals, granting naturalization "easily," or a high score on the Freedom House Index seem to be not-related to immigration figures. At first sight, there is some influence from the presence of legislation against discrimination: countries with such legislation (mostly in Northern Europe) tend to attract fewer immigrants. This finding, however, does not prove to be stable: if we exclude the countries where we do not have full-time series on unemployment, the relation disappears.

${ }^{6}$ We would like to thank the anonymous reviewers for this journal for suggesting this additional information in the model. 
Including political and historical variables, therefore, does not seem to add much to the statistical analysis of the theoretical approaches we want to discuss here. This does not imply, of course, that state policies do not matter. First of all, it should be mentioned that it is hard to discover significant effects of variables at the country level, given that our analysis only includes 21 countries. In other words, it is possible that the role of state policies does play an important role, but that we fail to discover it because of lack of statistical power. Second, state policies mediate the effect of the labor market and colonial linkages we discovered in paragraphs 6 and 7. It is not unlikely that the states functions as a gatekeeper, regulating immigration flows to fulfill the needs of the labor market. However, up till this moment, we have no empirical evidence to corroborate this process. Furthermore, it should be noted that government policies also can have an effect on economic prosperity and/or unemployment figures, so that in an indirect manner, too, government policies will still have an effect on immigration figures.

Our conclusion is that, with the data that are available thus far, it is not possible to develop an adequate and comprehensive measurement of state policies in the field of integration, migration, and discrimination policies. Several information-gathering efforts are under way (see, e.g., Bell, Chopin, and Palmer, 2006), so we do hope that our understanding of the effect of government policies can continue to grow in the years ahead.

\section{AN INTEGRATED MODEL}

Finally, we can now arrive at the construction of a more integrated model, simultaneously entering all the independent variables that proved to be significant in our earlier analyses. Again, time and population of the host country are included as control variables. From the economic analysis we keep the strongest variable, which is unemployment at $t-1$. From the cultural model, we keep the population of the former colonies. Given the fact that our network model did not lead to significant results, we did not include any variables from that model. Since none of our political or historical variables proved to be stable and significant, they too were not included in this final model.

Our final model, therefore, can be considered a simultaneous test for the economic and cultural models we discussed in our literature section (Table 10). The model shows that both our time variables do not have a significant effect. Self-evidently we have seen in Table 1 that migration flows tend to increase over time, but apparently we can explain this increase by our other independent 
TABLE 10

an Integrated Model for Pull Factors in Migration

\begin{tabular}{lccrr}
\hline \hline Fixed Effects & Estimate & SE & t-value & p-value \\
Intercept & 0.006 & 0.271 & 0.02 & 0.9817 \\
Time & -0.284 & 0.358 & -0.79 & 0.4386 \\
Time $^{2}$ & 0.356 & 0.239 & 1.49 & 0.1530 \\
Population host country $_{\text {Unemployment t }-1}$ & 0.420 & 0.090 & 4.66 & $<.0001$ \\
Pop. former colonies & -0.126 & 0.056 & -2.25 & 0.0252 \\
Random Effects & 0.109 & 0.041 & 2.62 & 0.0094 \\
Variance random intercept & Estimate & $\mathrm{SE}$ & $\mathrm{z}$-value & $\mathrm{p}$-value \\
Variance random slope time & 1.511 & 0.547 & 2.76 & 0.0029 \\
Variance random slope time $^{2}$ & 2.882 & 1.303 & 2.21 & 0.0135 \\
Residual variance $^{2}$ & 1.391 & 0.574 & 2.42 & 0.0077 \\
\hline
\end{tabular}

Note: Entries are results from a general linear mixed model for 1980-2004 immigration flows to European countries. $\mathrm{N}=296$.

variables, so that the time variables themselves remain not significant. Second, the population of the host country remains strongly significant, showing that large countries attract more immigrants than small countries. However, we were mainly interested in the final two variables: unemployment and colonial past. Both variables remain significant and the strength of the parameters is roughly the same $(-0.126$ versus 0.109$)$. This implies that both the economic and cultural frameworks turn out to be complementary rather than mutually exclusive: they both possess a certain validity. The unemployment variable is just slightly more powerful but this difference should not be overinterpreted. The model presented in Table 10 is more than satisfying: it explains $26.7 \%$ of the variance between year observations (level I) and $26.9 \%$ of the variance at the country level (level II). Using the entire 1980-2004 OECD data set we can therefore safely arrive at the conclusion that European countries receive more immigrants if their unemployment rates are lower. Typically, immigration flows react within a year to a shortage on the labor market. Second, the former colonial powers still attract significantly more immigrants than countries without a former colonial past. This finding is consistent with theories on enduring patterns of cultural hegemony. To express our findings in a more formal manner, our conclusion could be that:

$$
\begin{aligned}
\mathrm{Q}(\text { Immigration })= & \beta_{0}+\beta_{1} \text { Population Host Country } \\
& +\beta_{2} \text { Unemployment }(\mathrm{T}-1) \\
& +\beta_{3} \text { Population Former Colonies }
\end{aligned}
$$

Or to put it differently: the number of immigrants a European country receives annually can be seen as the function of a constant, combined with the 
population figure of the country itself, the unemployment rate in the previous year, and the combined population figure of all the former colonies.

\section{DISCUSSION AND CONCLUSIONS}

Massey et al. (1998) already noticed that we have access only to a "fragmented set of theories" to explain migration patterns. The ambition of this article has been to integrate these various approaches and to integrate them in a fully comparative model. This model was developed by using the OECD data set on migration trends for the 1980-2004 period. While we do have some doubts regarding the validity of this data set, it is striking that we found some very clear and significant results, indicating that this data set maybe is not 100 percent reliable, as various authors have indicated, but that nevertheless the data set can be used to reconstruct clear structures in the flow of migrant populations in Europe. Our results indicate that both the economic and the cultural approach can help us to determine the structure of migration patterns. With regard to the economic factor, it seems clear that potential immigrants do not systematically select countries with the highest GDP nor do they seem particularly attracted to countries with a generous social security system. In the current social and political debate on migration in Europe, these findings can have a particular relevance. Immigrants, on the other hand, do seem clearly attracted by shortages in the labor market, exactly as economic theory would predict. They even react quite efficiently to labor market shortages with a time lag of approximately one year. It has to be remembered here that we only take into account official immigration figures. With regard to undocumented immigrants, we can assume that they will not be attracted by social expenditure level since they mostly are excluded from receiving social benefits. Illegal migrants, however, are also known to respond to signals from the (informal) labor market. Therefore, if we could arrive at a general measurement of immigration, including legal and illegal immigrants, this would probably even strengthen the power of labor market variables. Such an estimate, however, is completely impossible given the absence of reliable figures on undocumented migration. Since we do not have sufficient information to include government policies in our models, we would urge further research on this specific relation.

An interesting question for further research, however, is how exactly the equilibrium between labor market incentives and immigration patterns is reached. To put it simply: how does someone in Ecuador find out that there is a job shortage in Spanish agriculture? Network position, active recruitment, or deliberate government policy might be possible mechanisms here, but this is to be further investigated in future research. 
Second, however, the former colonial past continues to play a role. Especially countries like Spain, Portugal, Italy, and France increasingly attract immigrants from their former colonies. For the UK the percentage of Commonwealth settlers is going down, but it remains on a very high level. A booming economy like Germany, a country with a limited colonial past, still seems to attract a relatively limited number of immigrants. Again, we only establish macro trends in this respect. It remains to be investigated why exactly immigrants are being attracted to the former colonial power. Partly, this might be an effect of language as our analysis demonstrates. For someone who was raised in a former French colony, it remains easier to relocate to France than to relocate to Germany. Government policy, too, might make a difference, granting a favored entry procedure to inhabitants of the former colonies. It also has to be remembered that communication and transportation lines are still being structured according to the colonial heritage. For example, direct flights from Kinshasa (Democratic Republic of Congo) are still controlled by French and Belgian airline companies, rendering it more plausible that citizens of Congo will arrive in France or Belgium, rather than in Germany or the UK. Again, this is a promising question for future research.

Looking back at the analysis, maybe the most interesting finding is that we succeeded in finding stable explanatory factors and in explaining a substantial proportion of the variance. First of all, this implies that the OECD figures may not be completely reliable, but that in any case there is a clear structure in them. At least the migration figures are significantly related to unemployment figures and we know that great care is being taken to standardize unemployment figures within OECD countries. But more substantively, it means that clear and well-defined pull factors are at work. Immigrants do not settle randomly, or in the "easiest" country. They are clearly attracted by shortages in the labor market, and by historical ties to a host country. The lessons to be learned from this finding are on the one hand that we cannot undo the former colonial history, but on the other hand that immigration seems to be an efficient mechanism to restore imbalances on the labor market. In the ongoing debate about the future immigration policy of Western European nations, we think these findings at least merit further consideration.

\section{REFERENCES}

Bell, M., I. Chopin, and F. Palmer

2006 Developing Anti-Discrimination Law in Europe. The 25 EU Member Countries Compared. Brussels: Migration Policy Group. 
Bengtsson, T., C. Lundh, and K. Scott

2005 "From Boom to Bust: The Economic Integration of Immigrants in Postwar Sweden." In European Migration: What Do We Know? Ed. K. Zimmermann. Oxford: Oxford University Press. Pp. 15-58.

Borjas, G.

1989 "Economic Theory and International Migration." International Migration Review 23:457-485.

1995 "The Economic Benefits from Immigration." Journal of Economic Perspectives $9(2): 3-22$.

Castles, S., and M. Miller

1994 The Age of Migration. 1st edn. Basingstoke, UK: Macmillan.

2003 The Age of Migration. 3rd edn. Basingstoke, UK: Palgrave.

Cornelius, W., T. Tsuda, P. Martin, and J. Hollifield, ed.

2004 Controlling Immigration. A Global Perspective. Stanford, CA: Stanford University Press.

DaVanzo, J.

1978 "Does Unemployment Affect Migration? Evidence from Micro Data." Review of Economics and Statistics 60(4):504-514.

Feld, S.

2005 "Labor Force Trends and Immigration in Europe." International Migration Review 39(3):637-662.

Hatton, T., and J. Williamson, ed.

1994 Migration and the International Labor Market, 1850-1939. London: Routledge.

Hatton, T., and J. Williamson

1998 The Age of Mass Migration. Causes and Economic Impact. Oxford: Oxford University Press. Kalter, F.

1998 "Partnerschaft und Migration. Zur Theoretischen Erklärung Eines Empirschen Effect." Kölner Zeitschrift für Soziologie und Sozialpsychologie 50(2):283-309.

Krieger, $\mathrm{H}$.

2004 Migration Trends in an Enlarged Europe. Dublin: European Foundation for the Improvement of Living and Working Conditions.

Krissman, F.

2005 "Sin Coyote Ni Patrón: Why the 'Migrant Network' Fails to Explain International Migration." International Migration Review 39(1):4-44.

Lemaître, G.

2005 The Comparability of International Migration Statistics. Statistics Brief 9. Paris: OECD.

Massey, D. et al.

1998 Worlds in Motion. Understanding International Migration at the End of the Millennium. Oxford: Clarendon Press.

OECD

2006 International Migration Outlook 2006. Paris: OECD.

Portes, A., and J. Böröcz

1989 "Contemporary Immigration: Theoretical Perspectives on Its Determinants and Modes of Incorporation.” International Migration Review 23(3):606-630. 
Portes, A., and R. Rumbaut

1996 Immigrant America: A Portrait. 2nd edn. Berkeley, CA: University of California Press.

Snijders, T., and R. Bosker

1994 "Modeled Variance in Two-Level Models." Sociological Methods and Research 22(3):342363.

Stalker, P.

2002 "Migration Trends and Migration Policy in Europe." International Migration 40(5):151179.

Stark, O.

1991 The Migration of Labour. Cambridge: Blackwell.

Venturini, A.

2004 Postwar Migration in Southern Europe, 1950-2000: An Economic Analysis. Cambridge: Cambridge University Press.

Verbeke, G., and G. Molenberghs

2000 Linear Mixed Models for Longitudinal Data. New York, NY: Springer.

Zlotnik, H.

1998 "International Migration 1965-96: An Overview." Population and Development Review 24(3):429-468. 